Check for updates

Cite this: RSC Adv., 2017, 7, 49309

Received 28th September 2017 Accepted 10th October 2017

DOI: 10.1039/c7ra10762e

rsc.li/rsc-advances

\section{One-pot synthesis of $\mathrm{MoS}_{2} / \mathrm{WS}_{2}$ ultrathin nanoflakes with vertically aligned structure on indium tin oxide as a photocathode for enhanced photo-assistant electrochemical hydrogen evolution reaction $\uparrow$}

\begin{abstract}
Xinxin Jiang, Baoliang Sun, Ye Song, Meiling Dou, Jing Ji* and Feng Wang (D)*
A hierarchical structure composed of vertically aligned ultrathin two dimensional (2D) $\mathrm{MoS}_{2} / \mathrm{WS}_{2}$ nanosheets is fabricated through a facile one-pot hydrothermal reaction. Scanning electron microscope (SEM), transmission electron microscope (TEM) and photoluminescence (PL) indicate that the $\mathrm{MoS}_{2} / \mathrm{WS}_{2}$ hybrid shows ultrathin nanoflakes with a thickness of 2-10 nm, and the as prepared heterostructure markedly enhances the separation of electro-hole pairs. Benefiting from the integrated W-doped $\mathrm{MoS}_{2}$, the vertically aligned nanostructure exhibits a moderate degree of disorder and increased active surface area. Electrochemical measurements (cyclic voltammetry (CV), linear sweep voltammetry (LSC) and electrochemical impedance spectroscope (EIS) under light illumination or in dark) indicated that the $\mathrm{MoS}_{2} / \mathrm{WS}_{2}$ hybrid (especially the hybrid with $\mathrm{Mo}: \mathrm{W}$ of $1 / 1$ ) exhibits much better photo-and electrochemical performance than its counterpart of pure $\mathrm{MoS}_{2}$ or $\mathrm{WS}_{2}$, which made it a promising photocathode for electrocatalytic hydrogen evolution reaction (HER) by photo-assistance.
\end{abstract}

\section{Introduction}

Investigation of photoelectrocatalytic activities in transition metal dichalcogenides (TMDs) has revealed a new category of photonic nanomaterials with potential applications in hydrogen evolution reaction (HER). ${ }^{1-16}$ These materials are characterized by a unique 2 dimensional (2D) structure of trigonal-prismatic metal centres with weak interlayer $\mathrm{S}-\mathrm{S}$ bonding. Among the TMDs, $\mathrm{WS}_{2}$ and $\mathrm{MoS}_{2}$ have an analogous structure and share similar physical and chemical properties. Both are the most interesting layered materials for HER because their hydrogen binding energy is close to that of Pt-group metals, ${ }^{17}$ and are considered as an alternative electrocatalyst to Pt-group metals towards the HER. ${ }^{18-22}$ In addition, their graphene-like structure possesses direct band gaps corresponding well to visible-to-near-IR photon energies, ${ }^{23}$ therefore, are much suitable in many optoelectronic applications. ${ }^{24-26}$

However, $\mathrm{MoS}_{2}$ or $\mathrm{WS}_{2}$ alone has negligible photocatalytic activity probably due to the fact that $\mathrm{MoS}_{2}$ or $\mathrm{WS}_{2}$ has a relative narrow band gap, and thus is liable to cause recombination of

State Key Laboratory of Chemical Resource Engineering, Beijing Key Laboratory of Electrochemical Process and Technology for Materials, Beijing University of Chemical Technology, Beijing 100029, China. E-mail: jijing@mail.buct.edu.cn; wangf@mail.buct.edu.cn

$\dagger$ Electronic supplementary information (ESI) available. See DOI: 10.1039/c7ra10762e photoinduced electron-hole. Up to now, most of $\mathrm{MoS}_{2}$ or $\mathrm{WS}_{2}$ based photoelectrocatalyst reported for HER applications concerned with traditional photocatalytic materials (e.g., $\mathrm{MoS}_{2} / \mathrm{CdS}$, $\mathrm{WS}_{2} / \mathrm{CdS},{ }^{27} \mathrm{MoS}_{2} / \mathrm{Cu}_{2} \mathrm{O},{ }^{28} \mathrm{MoS}_{2} /$ graphene/CdS, ${ }^{29} \mathrm{MoS}_{2} / \mathrm{TiO}_{2}{ }^{30}$ etc.).

Theoretical calculations have shown that $\mathrm{MoS}_{2} / \mathrm{WS}_{2}$ heterostructures present an ideal energy band alignment of type-II semiconductors which is in favor of the separation of photoinduced electron-hole pairs. ${ }^{31,32}$ And some investigations have quantitatively analysed and probed the model heterostructure $\mathrm{MoS}_{2} / \mathrm{WS}_{2}$ concerning with the $2 \mathrm{D}$ spatial distributions of the built in potential and the related electronic structure. ${ }^{33,34}$ Therefore, the cocatalyst of coupling of $\mathrm{MoS}_{2}$ with $\mathrm{WS}_{2}$ has the potential in the applications of photocatalysis.

On the other hand, the photo-and electrocatalytic activities can be improved by ways of tuning the morphologies of TMDs. Since previous experiments ${ }^{35-37}$ and density function theory studies ${ }^{38}$ have shown that the edges of $\mathrm{MoS}_{2}$ were identified as active sites for the $\mathrm{HER}$, and both $\mathrm{WS}_{2}$ and $\mathrm{MoS}_{2}$ show morphology-dependent photo- and electrocatalytic activities, ${ }^{39-43}$ a large body of work has been directed at design and control of the morphologies and microstructures. Specifically, the investigations focused on controllable growth of $\mathrm{MoS}_{2}$ or $\mathrm{WS}_{2}$ nanostructures, especially as nanoparticles and mono-orfewer layers that maximally expose active edge sites to the reactants, and optimization of the number of active sites by elemental doping TMDs. ${ }^{4-47}$ 
From the view point of electrocatalytic kinetics, vertically aligned 2D nanostructures on the conductive substrate is an ideal morphology for enhancing the photoelectrocatalytic activity due to their abundant active sites ${ }^{48}$ large specific surface and easy electron transportation. Many different synthesis methods for the preparation of vertically aligned TMD-based 2D structured materials have been explored. However, the preparation of vertically aligned 2D nanosheets usually grows on the carbon based ${ }^{49,50}$ or porous substrate ${ }^{51}$ through multi-step synthetic processes, which find an application only in electrocatalysis for HER. In addition, most photo or electrocatalysts are prepared in form of powder assemblies, and require binder to prepare the electrodes. The related photo- or eletrocatalytic reaction is conducted either under open-circuit conditions (the electron and hole transport at the same electrode) using power suspensions or catalyst fixed on a support (especially for the electrocatalyst for HER, which is generally used as the cathode), or alternatively in a photo-electrochemical setting in which bias potential is applied to enhance the photocurrent.

To make use of the integration of electro- and photocatalytic activities as a superior photoelectrocatalyst for PEC cells, vertically aligned nanostructure of ultrathin $2 \mathrm{D} \mathrm{MoS}_{2} / \mathrm{WS}_{2}$ nanosheets which is directly grown on transparent indium tin oxide (ITO) substrates is very critical, since they are compatible with the direct photocatalytic applications. This hybrid structure not only favors light harvesting and adsorption, but also is beneficial to fast electron transportation, ion diffusion and sufficient electrochemical reaction of individual nanostructures due to enriched active sites and binder free combination.

In this work, hierarchical structures composed of vertically aligned ultrathin 2D $\mathrm{MoS}_{2} / \mathrm{WS}_{2}$ nanosheets were fabricated through a facile one-pot hydrothermal reaction. By this approach, the whole scale of vertically grown ultrathin $\mathrm{MoS}_{2} /$ $\mathrm{WS}_{2}$ sheets was fabricated directly on ITO substrate. Herein, the hybrid nanosheets of $\mathrm{MoS}_{2} / \mathrm{WS}_{2}$ supplied numbers of active sites with proper defects since the elements of Mo and $\mathrm{W}$ doped with each other. More meaningful, favorable band alignment, as well as intimate $\mathrm{p}-\mathrm{n}$ heterojunction between $\mathrm{MoS}_{2}$ and $\mathrm{WS}_{2}$, provides an effective carrier separation in this composite based photoelectric device. Consequently, the as-synthesized composites of $\mathrm{MoS}_{2} / \mathrm{WS}_{2}$ nanosheets shows better visible light activities than that of either pure $\mathrm{WS}_{2}$ or $\mathrm{MoS}_{2}$ nanostructures and shows great potential for integration of electro- and photocatalysis as a superior photoelectrocatalyst for PEC cells.

Up to now, the investigations on $\mathrm{MoS}_{2} / \mathrm{WS}_{2}$ composites mainly focused on the electronic structure of the model heterostructure, and little attention has been given to the influence of the as prepared nanostructures on their photo-and electrocatalytic activities. Among the few literatures related to the photoelectrocatalysis of RHE for $\mathrm{MoS}_{2} / \mathrm{WS}_{2}$ composites (Table 1), the photoelectrocatalytic activity is far from satisfactory, and still needs to be improved. The rational use of the $\mathrm{MoS}_{2} / \mathrm{WS}_{2}$ cathode provided a new avenue toward achieving an enhanced electrocatalytic activity by photo-assistance.

\section{Experimental section}

\subsection{Materials}

Sulfuric acid was purchased from Sinopharm Chemical Reagent Co., Ltd. Sodium molybdate dehydrate, sodium tungstate dehydrate and thioacetamide was obtained from J\&K. Indium tin oxide (ITO) coated glass was purchased from China South Glass. Deionized water (resistivity $>18.4 \mathrm{M} \Omega \mathrm{cm}^{-1}$ ) was prepared using a pure water system (TTL-6B). All chemical reagents were used without further purification.

\subsection{Preparation of $\mathrm{MoS}_{2} / \mathrm{WS}_{2}$ vertical mesh-shaped structure}

A simple hydrothermal method was preferred to prepare the vertical aligned $\mathrm{MoS}_{2} / \mathrm{WS}_{2}$ ultrathin sheets on the ITO substrate. The ITO substrate was ultrasonically cleaned in acetone, ethanol and deionized (DI) water for $15 \mathrm{~min}$ each, respectively, prior to use. In a typical reaction, a $2 \times 4 \mathrm{~cm}^{2}$ area of the ITO substrate was placed vertically at the bottom of the Teflon-lined stainless-autoclave $(25 \mathrm{ml})$ and immersed in a solution composing of $0.0086 \mathrm{mmol}$ of $\left(\mathrm{NH}_{4}\right)_{6} \mathrm{Mo}_{7} \mathrm{O}_{24} \cdot 4 \mathrm{H}_{2} \mathrm{O}, 0.06 \mathrm{mmol}$ of $\mathrm{Na}_{2} \mathrm{WO}_{4} \cdot 2 \mathrm{H}_{2} \mathrm{O}$ and $0.4 \mathrm{mmol}$ of $\mathrm{L}$-cystine. And then, the autoclave was sealed and thermally treated at $220{ }^{\circ} \mathrm{C}$ for 20 hours. The as-prepared sample of vertically aligned $\mathrm{MoS}_{2} / \mathrm{WS}_{2}$ hybrid nanosheets (labelled $\mathrm{MoS}_{2} / \mathrm{WS}_{2}$ ) was then removed from the solution, washed thoroughly with ethanol and distilled water, and dried naturally. In control experiments, the vertically aligned pristine $\mathrm{MoS}_{2}$ and $\mathrm{WS}_{2}$ structures on the ITO substrate were prepared by the similar hydrothermal method, respectively, with that of $\mathrm{MoS}_{2} / \mathrm{WS}_{2}$ nanosheets, except that the ITO is immersed in a solution composing of $0.0172 \mathrm{mmol}\left(\mathrm{NH}_{4}\right)_{6}$ $\mathrm{Mo}_{7} \mathrm{O}_{24} \cdot 4 \mathrm{H}_{2} \mathrm{O}$, or $0.12 \mathrm{mmol} \mathrm{Na}_{2} \mathrm{WO}_{4} \cdot 2 \mathrm{H}_{2} \mathrm{O}$ and $0.4 \mathrm{mmol} \mathrm{L-}$ cystine. In control experiments, the precursors of $\mathrm{MoS}_{2}$ and $\mathrm{WS}_{2}$ are stoichiometrically fed into the reaction system in mole ratio of $2: 1,1: 1$, and $1: 2$ for $\mathrm{Mo} / \mathrm{W}$, which is designated as the mole ratio of Mo and $\mathrm{W}(2: 1),(1 / 1)$ and (1/2), respectively. It is notably that the concentration of $\left(\mathrm{NH}_{4}\right)_{6} \mathrm{Mo}_{7} \mathrm{O}_{24} \cdot 4 \mathrm{H}_{2} \mathrm{O}$ remains constant regardless of the mole ratio of $\mathrm{Mo} / \mathrm{W}$.

\subsection{Characterization}

Scanning electron microscopy (SEM) investigation was conducted by a JEOL-6701F field emission scanning electron microscope which is operated at a scanning current of $10 \mu \mathrm{A}$ and an accelerating voltage of $5 \mathrm{kV}$. High resolution transmission electron microscopy (HRTEM) is performed by a JEOL JSM-3010 instrument operated at $200 \mathrm{kV}$. High-angle annular dark-field scanning transmission electron microscopy (HAADFSTEM) and corresponding energy dispersive spectroscopy (EDS) mapping analysis were carried out on a JEOL JEM-2010F STEM. The crystal phases of the samples were collected on an X-ray diffractometer with $\mathrm{Cu}-\mathrm{K}$ radiation at a scan rate of $5^{\circ} \mathrm{min}^{-1}$ (Rigaku D/max-2500B2+/PCX). X-ray photoelectron spectroscopy (XPS) was performed on the as-synthesized samples using a ESCALAB 250 XPS system with an Al K $\alpha$ source (Thermo Fisher Scientific USA). UV-visible diffuse reflectance spectra were recorded using a UV-visible spectrophotometer with an 
Table 1 Comparison of hydrogen evolution data of $\mathrm{WS}_{2} / \mathrm{MoS}_{2}$ composites compared with few of the literature reports

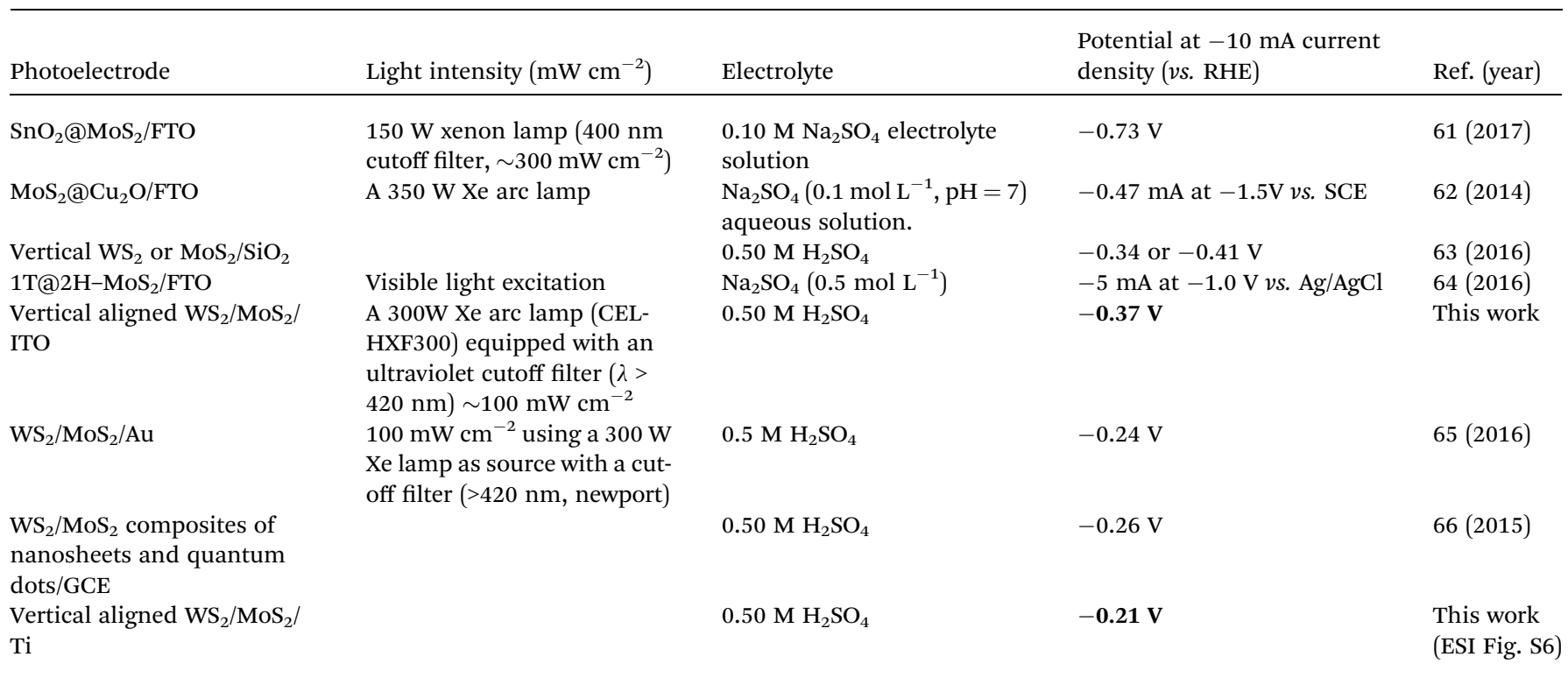

integrating sphere (Shimadzu UV2450, Japan). Photoluminescence measurements (PL) were carried out on a Hitachi F-4500 FL spectrophotometer at an excitation wavelength of $400 \mathrm{~nm}$.

\subsection{Electrochemical measurements}

Electrochemical experiments were performed in a threeelectrode cell in which a Pt plate and calomel were used as the counter and reference electrodes, respectively, and the as prepared samples were employed as the working electrode with an area of $0.16 \mathrm{~cm}^{2}$. All the samples were analysed in $0.50 \mathrm{M}$ $\mathrm{H}_{2} \mathrm{SO}_{4}$ solution $(\mathrm{pH}=0.48)$. A 300W Xe arc lamp (CEL-HXF300) equipped with an ultraviolet cutoff filter $(\lambda>420 \mathrm{~nm})$ was utilized as the visible light source with $150 \mathrm{~mW} \mathrm{~cm}{ }^{-2}$ incident light intensity. Linear sweep voltammetry (LSV) with scan rate of $10 \mathrm{mV} \mathrm{s}^{-1}$ was conducted by an electrochemical workstation (CHI660E, Chenhua, China). All the potentials were transformed into the reversible hydrogen electrode (RHE) according to the Nernst equation:

$E(v s . \mathrm{RHE})=E(v s . \mathrm{SCE})+0.0591 \mathrm{pH}+E_{\mathrm{SCE}}^{0} \cdot E_{\mathrm{SCE}}^{0}=0.245 \mathrm{~V}$ at $25{ }^{\circ} \mathrm{C}$. EIS measurements were performed at an overpotential of $-0.559 \mathrm{~V} v s$. RHE over frequency range from $10^{-1}$ to $10^{5} \mathrm{~Hz}$. Electrochemical capacitance measurements were conducted by cyclic voltammetry (CV) for two cycles between 0.1 and $0.2 \mathrm{~V} v$ s. RHE with scanning rates of $60,80,100,120$ and $150 \mathrm{mV} \mathrm{s}^{-1}$.

\subsection{Photocatalytic activity measurement for HER}

The photocatalytic $\mathrm{H}_{2}$ production reactions of photocatalysts were carried out under open-circuit conditions (electron and hole transfer occur from the same electrode) using $\mathrm{MoS}_{2} / \mathrm{WS}_{2}$ layers fixed on an ITO support $\left(8 \mathrm{~cm}^{2}\right)$. Specifically, the photocatalytic $\mathrm{H}_{2}$ evolution is conducted in an outer irradiation-type photoreactor (Pyrexglass) connected to a closed gas-circulation system. The catalyst samples were put into $20 \mathrm{ml}$ of aqueous solution containing $0.50 \mathrm{M} \mathrm{H}_{2} \mathrm{SO}_{4}$ solution. The catalysts were irradiated with a $300 \mathrm{~W}$ Xe arc lamp (CEL-HXF300). The photocatalytic $\mathrm{H}_{2}$ evolution rate was analyzed with an online gas chromatograph (GC-7920, TCD detector).

\section{Results and discussion}

\subsection{Structure characterization}

SEM and HRTEM. SEM images of the pristine $\mathrm{WS}_{2}$, pristine $\mathrm{MoS}_{2}$ and $\mathrm{MoS}_{2} / \mathrm{WS}_{2}$ hybrid nanosheets are presented in Fig. 1. As shown in Fig. 1a-c, all the prepared samples are well distributed and vertically grown on the ITO substrate. Individual $\mathrm{WS}_{2}$ or $\mathrm{MoS}_{2}$ nanosheet was estimated to be dozens of nanometers in thickness, much thicker than that of $\mathrm{MoS}_{2} / \mathrm{WS}_{2}$ hybrid. The SEM images of $\mathrm{MoS}_{2} / \mathrm{WS}_{2}$ catalyst of different Mo : W ratios display similar morphologies (Fig. S1 $\dagger$ ). More details of the morphology and microstructure of the $\mathrm{MoS}_{2} / \mathrm{WS}_{2}$ hybrid nanosheets can be obtained from their TEM and HRTEM surveys shown in Fig. 2a-c. As revealed in Fig. 2b, a single $\mathrm{MoS}_{2} /$ $\mathrm{WS}_{2}$ hybrid nanosheet consists of 2 to 10 layers, less than $10 \mathrm{~nm}$, and each interlayer distance is characterized by $\sim 0.62 \mathrm{~nm}$ (002). The lattice-resolved HRTEM image shown in Fig. 2c, enclosed by red boxes, and the corresponding FFT pattern indicate the highly crystalline characteristics and undoubtedly attributes to the hexagonal characteristics of the $2 \mathrm{H}-\mathrm{MoS}_{2}$ (upper right). In addition, the HRTEM image of the $\mathrm{MoS}_{2} / \mathrm{WS}_{2}$ hybrid nanosheets shown in Fig. 2c, enclosed by dark blue boxes, show some trigonal lattice area (octahedral coordination) of the $1 \mathrm{~T}$ phase besides the common honey-comb lattice area of the trigonal prismatic coordination in the $2 \mathrm{H}$ phase. Nevertheless, the FFT of Fig. 2c (lower right) does not reveals the perfect hexagonal packing usually observed for $2 \mathrm{H}$ structure due to the overlap with the 1T structure. Furthermore, Raman spectra (Fig. S2 $\dagger$ ) show a set of characteristic peaks for $\mathrm{MoS}_{2}$ nanosheets at $375 \mathrm{~cm}^{-1}, 403 \mathrm{~cm}^{-1}$ and $445 \mathrm{~cm}^{-1}$ arising from the $\mathrm{E}_{2 \mathrm{~g}}^{1}, \mathrm{~A}_{1 \mathrm{~g}}$ and longitudinal acoustic phonon modes, ${ }^{52,53}$ 

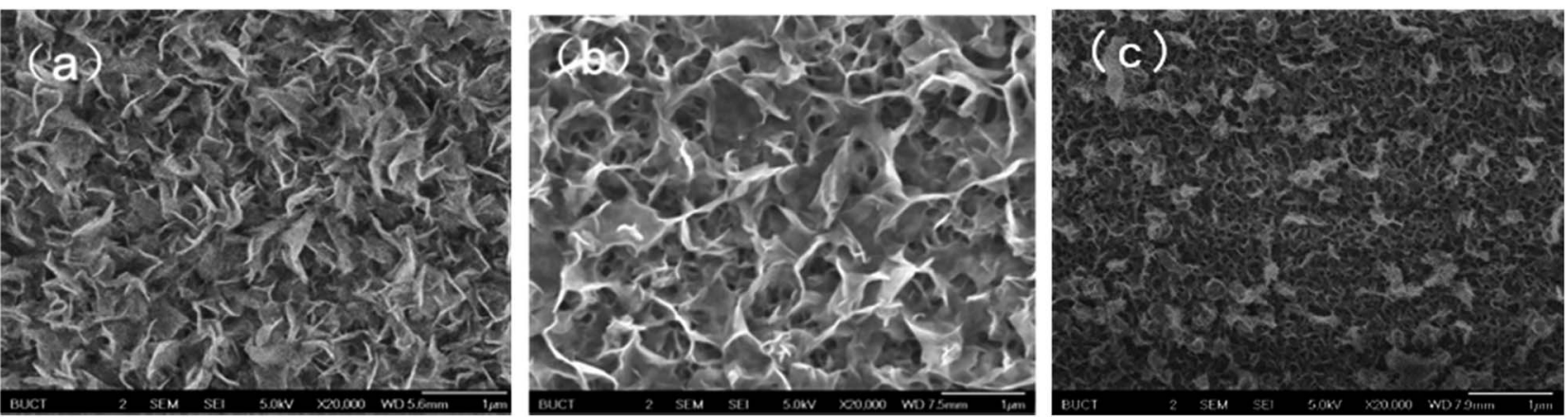

Fig. 1 SEM images of (a) $\mathrm{WS}_{2}$, (b) $\mathrm{MoS}_{2}$ and (c) $\mathrm{MoS}_{2} / \mathrm{WS}_{2}$ hybrid nanosheets. The calculated mole ratio of Mo:W is $1: 1$.

respectively, which corresponds to the presence of the $2 \mathrm{H}$ phase. The peaks at $220 \mathrm{~cm}^{-1}$ is ascribed to the $1 \mathrm{~T}-\mathrm{MoS}_{2}$ phase, suggesting the existence of $1 \mathrm{~T}$ phase ingredient embedded in the $2 \mathrm{H}-\mathrm{MoS}_{2}$ host. $^{54} 1 \mathrm{~T}-\mathrm{MoS}_{2}$ nanosheets show higher HER catalytic activity than $2 \mathrm{H}-\mathrm{MoS}_{2}$ (ref. 12, 54 and 55) due to its metallic characteristics. ${ }^{56}$ The fringe spacings of $0.27,0.227$, and $0.247 \mathrm{~nm}$ correspond to the (100), (103) and (102) planes of $\mathrm{MoS}_{2}$, respectively.

The formation of $1 \mathrm{~T}-\mathrm{MoS}_{2}$ is due to the intercalation of ammonia-ions, thus leading to the release of free $1 \mathrm{~T}-\mathrm{MoS}_{2}$ nanosheets. ${ }^{57}$ Nevertheless, the precursor of $\mathrm{W}$ source of $\mathrm{Na}_{2}$ $\mathrm{WO}_{4} \cdot 2 \mathrm{H}_{2} \mathrm{O}$ is only beneficial to the formation of $2 \mathrm{H}$ structure ${ }^{58}$

Furthermore, we carried out elemental mapping and energydispersive X-ray spectroscopy (EDS) under scanning transmission electron microscopy (STEM) to probe the composition and spatial distribution of the constituent elements. Fig. $2 \mathrm{~d}$ and $\mathrm{e}$ showed the intimate contact between $\mathrm{WS}_{2}$ and $\mathrm{MoS}_{2}$ by showing a perfect spatial correspondence and homogeneous $\mathrm{S}$ element distribution. More meaningful, the co-existence of the $\mathrm{W}$ and Mo element are both uniformly distributed with each other. The energy-dispersive spectrum (EDS) (Fig. 2e) of the hybrid confirms the coexistence of $\mathrm{Mo}, \mathrm{W}$ and $\mathrm{S}$, and the atomic ratio of $\mathrm{S}: \mathrm{Mo}: \mathrm{W}$ is $58.3: 26.1: 1.1$, respectively. A relative small ratio of $\mathrm{W}$ indicates that the element of $\mathrm{W}$ doped $\mathrm{MoS}_{2}$, and $\mathrm{WS}_{2}$ is successfully implanted in the $\mathrm{MoS}_{2}$ nanosheet matrix. However, the small ratio of $\mathrm{W}$ determined by EDS in the hybrid is obviously not consistent with the stoichiometric feeding ratio of $1 / 1$. This is because $\mathrm{Mo}^{4+}$ and $\mathrm{W}^{4+}$ have difference in affinity to sulphur ${ }^{59}$ The equilibrium constant of Mo-sulfidation is two orders of magnitude higher than that of $\mathrm{W}$-sulfidation. ${ }^{\mathbf{6 0 , 6 1}}$ Therefore, the constituent proportion of $\mathrm{MoS}_{2}$ is much higher than that of $\mathrm{WS}_{2}$ in the composite.

XRD patterns. The X-ray powder diffraction (XRD) patterns of the as prepared samples confirmed the identity of the hexagonal $\mathrm{WS}_{2}$ phase in all $\mathrm{MoS}_{2} / \mathrm{WS}_{2}$ samples (Fig. 3), and all the reflections at $2 \theta=14.3^{\circ}, 28.9^{\circ}$ and $33.6^{\circ}$ can be assigned to the (002), (004) and (101) planes of hexagonal $\mathrm{WS}_{2}$ (JCPDS \#841398), respectively. However, the characteristic peak for $\mathrm{MoS}_{2}$ (002) was difficult to be distinguish from that of $\mathrm{WS}_{2}$ due to their similar reflection position around $14.5^{\circ}$. In addition, the reflection for $1 \mathrm{~T}$ phase of $\mathrm{MoS}_{2}$, which generally showed typical peak splitting over (002), shifting to lower angles ${ }^{57}$ is not detected. This is properly due to the fact that the content of $1 \mathrm{~T}$ phase is too low to be detected by XRD technique.

The as-prepared $\mathrm{MoS}_{2} / \mathrm{WS}_{2}$ samples were further analyzed with XPS analysis (Fig. 4). The binding energies for each element are used to identify the individual elements due to their distinct values. In Fig. 4a, the XPS survey spectrum that Mo, W and $\mathrm{S}$ elements coexist in the surface elemental composition. Fig. $4 \mathrm{~b}-\mathrm{d}$ revealed a series of high-resolution XPS spectra of $\mathrm{W}$ 4f, Mo 3d, and S 2p. As presented in Fig. 4d, the S 2p peak splits into two peaks at $162.1 \mathrm{eV}$ and $163.3 \mathrm{eV}$, which is corresponding to $S 2 p_{3 / 2}$ and $S 2 p_{1 / 2}$, respectively. Two peaks of Mo $3 d_{3 / 2}$ at $232.9 \mathrm{eV}$ and Mo $3 \mathrm{~d}_{5 / 2}$ at $229.7 \mathrm{eV}$ are typical characteristics of Mo 3d, and the other two peaks observed at 231.6 and $228.1 \mathrm{eV}$ are ascribed to Mo $3 \mathrm{~d}_{3 / 2}(1 \mathrm{~T})$ and Mo $3 \mathrm{~d}_{5 / 2}(1 \mathrm{~T})$, respectively (Fig. 4c).

Two main peaks of $\mathrm{W}^{4+}$ in $\mathrm{WS}_{2}$ are at the binding energies of 32.7 and $34.9 \mathrm{eV}$, which is the semiconducting prismatic $2 \mathrm{H}$ form. ${ }^{62,63}$ Upon further scrutiny, $\mathrm{W}^{6+}$ was observed are at $37.3 \mathrm{eV}$, which are due to the presence of $\mathrm{WO}_{3} \cdot{ }^{64}$

Optical properties (PL and UV-vis). To investigate the visiblelight absorption for the $\mathrm{MoS}_{2} / \mathrm{WS}_{2}$ hybrid nanosheets, we conducted an UV-visible absorption spectra experiment, as shown in Fig. 5a, and calculated the bandgap $\left(E_{\mathrm{g}}\right)$ of the as-prepared samples (Fig. S3†). For comparison, the light absorption and related $E_{\mathrm{g}}$ of the pristine $\mathrm{WS}_{2}$ and $\mathrm{MoS}_{2}$ are also included. According to UV-vis. spectra, all of the samples have absorption with wavelengths ranging from 350 to $600 \mathrm{~nm}$ (Fig. 5a). In comparison with the pristine $\mathrm{WS}_{2}$ or $\mathrm{MoS}_{2}, \mathrm{MoS}_{2} / \mathrm{WS}_{2}$ showed significantly increased adsorption intensity, and the $\mathrm{MoS}_{2} / \mathrm{WS}_{2}$ with $\mathrm{Mo} / \mathrm{W}$ mole ratio of $1: 1$ exhibits the strongest adsorption. In addition, the resulting $E_{\mathrm{g}}$ values for $\mathrm{WS}_{2}, \mathrm{MoS}_{2}$ and $\mathrm{MoS}_{2} /$ $\mathrm{WS}_{2}(1: 1)$ are 1.59, 1.80 and $1.67 \mathrm{eV}$, (Fig. S3†) respectively. In this context, both $\mathrm{WS}_{2}$ and $\mathrm{MoS}_{2}$ exhibit a small increase in the band gap, not well consistent with the theoretical bandgap of fewer layers $\mathrm{WS}_{2}$ or $\mathrm{MoS}_{2}(\sim 1.3 \mathrm{eV})$. The increase in the band gap is properly attributed to the effect of the $E_{\mathrm{g}}$ of $\operatorname{In}_{2} \mathrm{~S}_{3}(\sim 2.4 \mathrm{eV})$ derived of ITO under hydrothermal condition (ESI Fig. S4 $\dagger$ ).

The PL spectra of $\mathrm{MoS}_{2}$ and $\mathrm{MoS}_{2} / \mathrm{WS}_{2}$ were measured at an excitation wavelength of $400 \mathrm{~nm}$ to assess the separation efficiency of photogenerated electron-hole pairs. According to the PL spectra shown in Fig. 5b, the PL intensity of the $\mathrm{MoS}_{2} / \mathrm{WS}_{2}$ heterostructure is much weaker than that of $\mathrm{MoS}_{2}$ or $\mathrm{WS}_{2}$, 

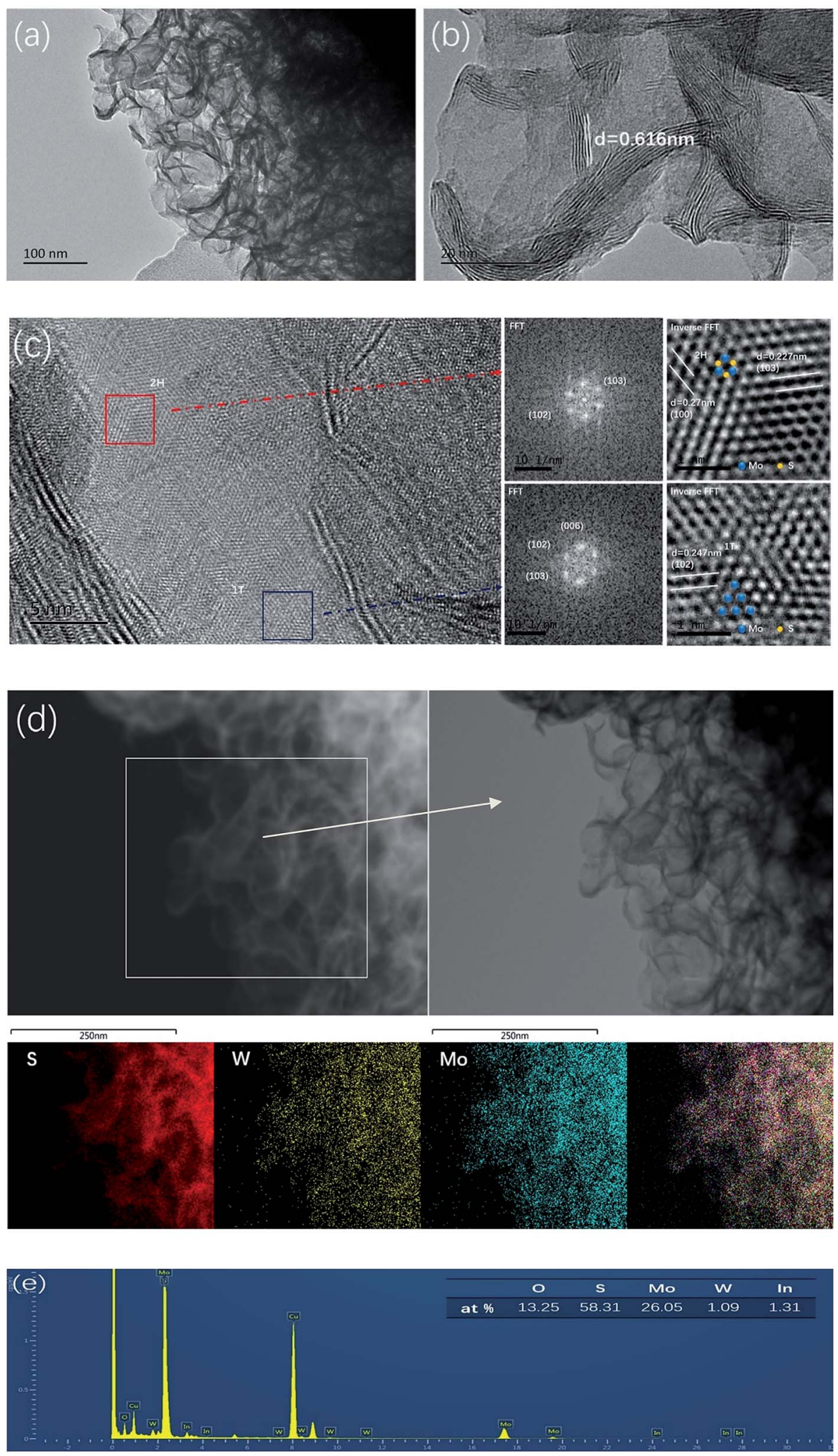

Fig. 2 (a) TEM images of $\mathrm{MoS}_{2} / \mathrm{WS}_{2}$, (b) HRTEM images, (c) HRTEM image of $\mathrm{MoS}_{2} / \mathrm{WS}_{2}$ with its corresponding Fast Fourier Transform (FFT), highlighting the random orientation of individual building blocks (evidenced by both the lattice fringes and the FFT ring pattern), (d) elemental mapping and (e) EDS spectrum of vertical aligned $\mathrm{MoS}_{2} / \mathrm{WS}_{2}$ structure. The calculated mole ratio of Mo:W is $1: 1$.

suggesting reduced recombination of photogenerated charge carriers under illumination. Apparently, the $\mathrm{MoS}_{2} / \mathrm{WS}_{2}$ heterostructure with mole ration of $1: 1$ shows the lowest PL intensity among all of the samples. With the reduced photogenerated charge carrier recombination and thus quick photogenerated charge carrier transportation and the interaction of the 


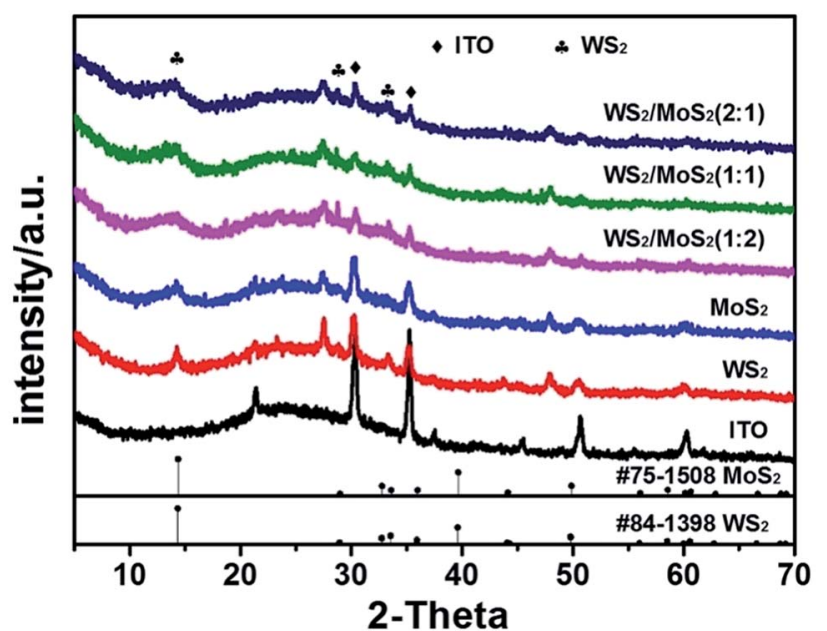

Fig. 3 XRD patterns of the as prepared samples. photoinduced electrons with $\mathrm{H}^{+}$in water occurs directly, the asprepared composite is anticipated to enhance the photocatalytic activity for HER.

To confirm the enhanced separation efficiency of photogenerated charge carriers, we measured the transient photocurrent (chronoamperometric) of the samples at bias of $0.372 \mathrm{~V}$ vs. RHE (Fig. 6). All of the samples exhibit good reproducibility of the photocurrent, and the intensity of $\mathrm{MoS}_{2} / \mathrm{WS}_{2}$ is much stronger than that of pristine $\mathrm{MoS}_{2}$ or $\mathrm{WS}_{2}$. The strongest photocurrent is obtained from the sample of $\mathrm{MoS}_{2} / \mathrm{WS}_{2}$ of $1: 1$. A higher photocurrent response of the composite suggests that heterostructures do has a higher separation efficiency of photogenerated electrons and holes. ${ }^{65}$

Additionally, operational stability is also an important criterion for a HER catalyst. To assess the stability of $\mathrm{MoS}_{2} / \mathrm{WS}_{2}$ for HER, a current density $v s$. time $(I-t)$ curve was recorded over a longer reaction time (ESI Fig. S5 $\dagger$ ) at $0.372 \mathrm{~V}$ (vs. RHE). As shown in Fig. S5, $\uparrow \mathrm{MoS}_{2} / \mathrm{WS}_{2}(\mathrm{Mo} / \mathrm{W}=1: 1)$ electrode showed
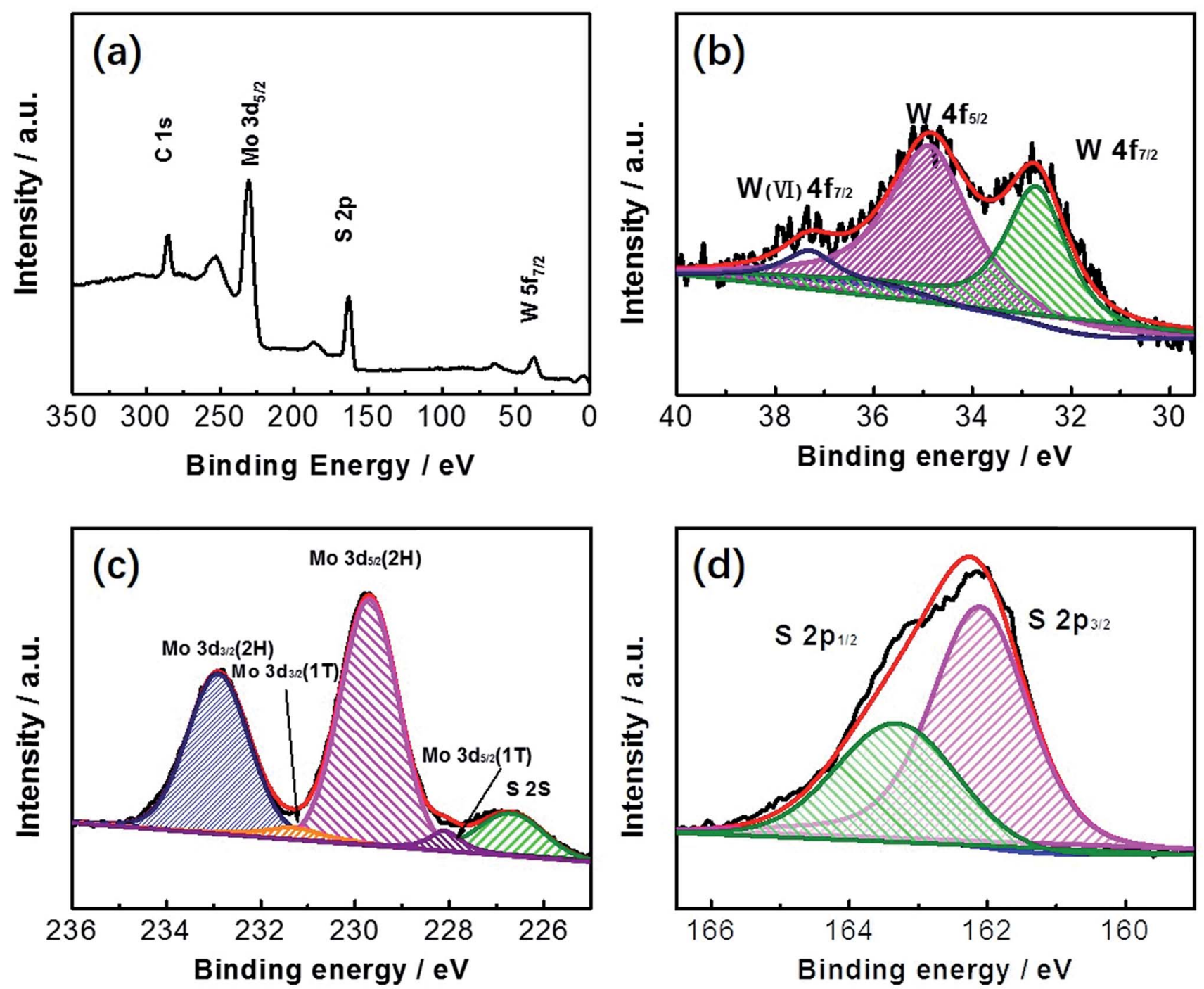

Fig. 4 (a) XPS spectrum of the $\mathrm{MoS}_{2} / \mathrm{WS}_{2}$ nanosheets, (b) high resolution XPS spectrum of Mo $3 \mathrm{~d}$, (c) high resolution XPS spectrum of W $3 \mathrm{~d}$, and (d) high resolution XPS spectrum of $S 2 p$. The calculated mole ratio of $M o: W$ is $1: 1$. 

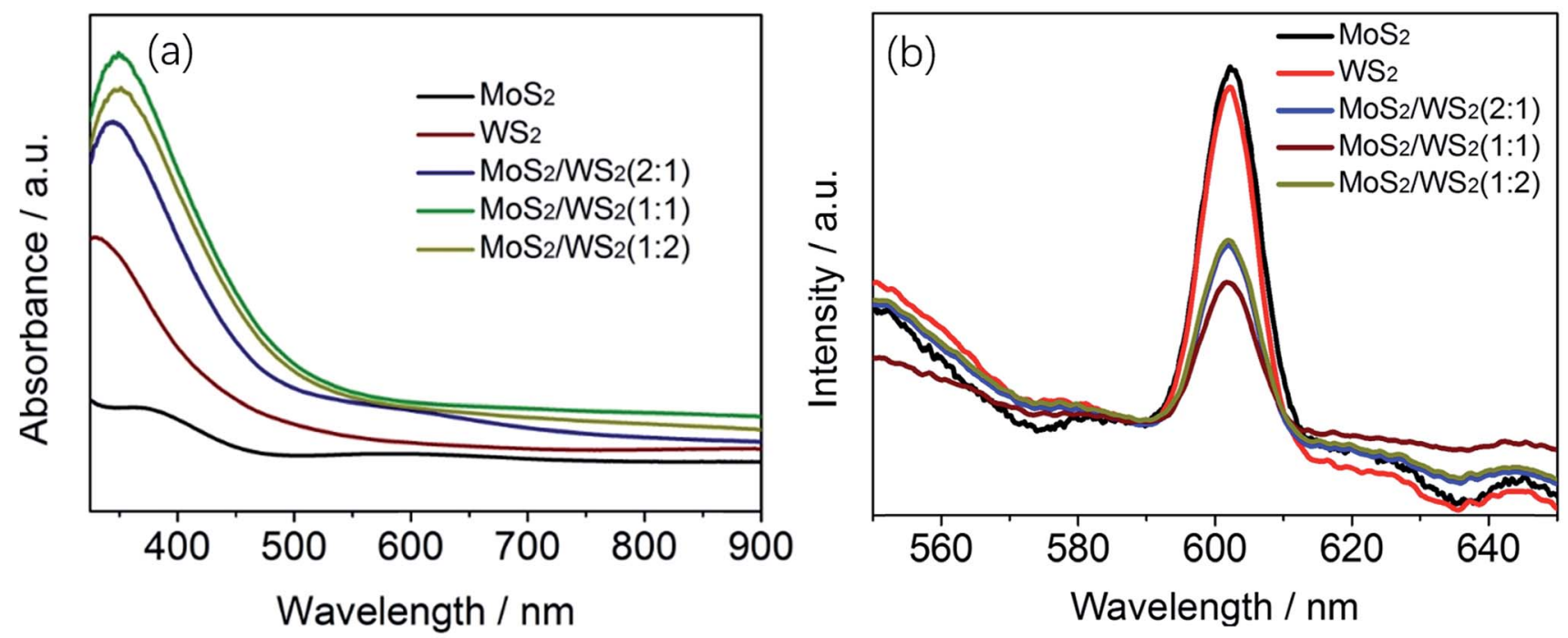

Fig. 5 (a) UV-visible absorption spectra of $\mathrm{MoS}_{2} / \mathrm{WS}_{2}(1 / 1)$, (b) PL spectra of $\mathrm{MoS}_{2} / \mathrm{WS}_{2}$ nanosheets with different stoichiometric mole ratio of Mo : W.

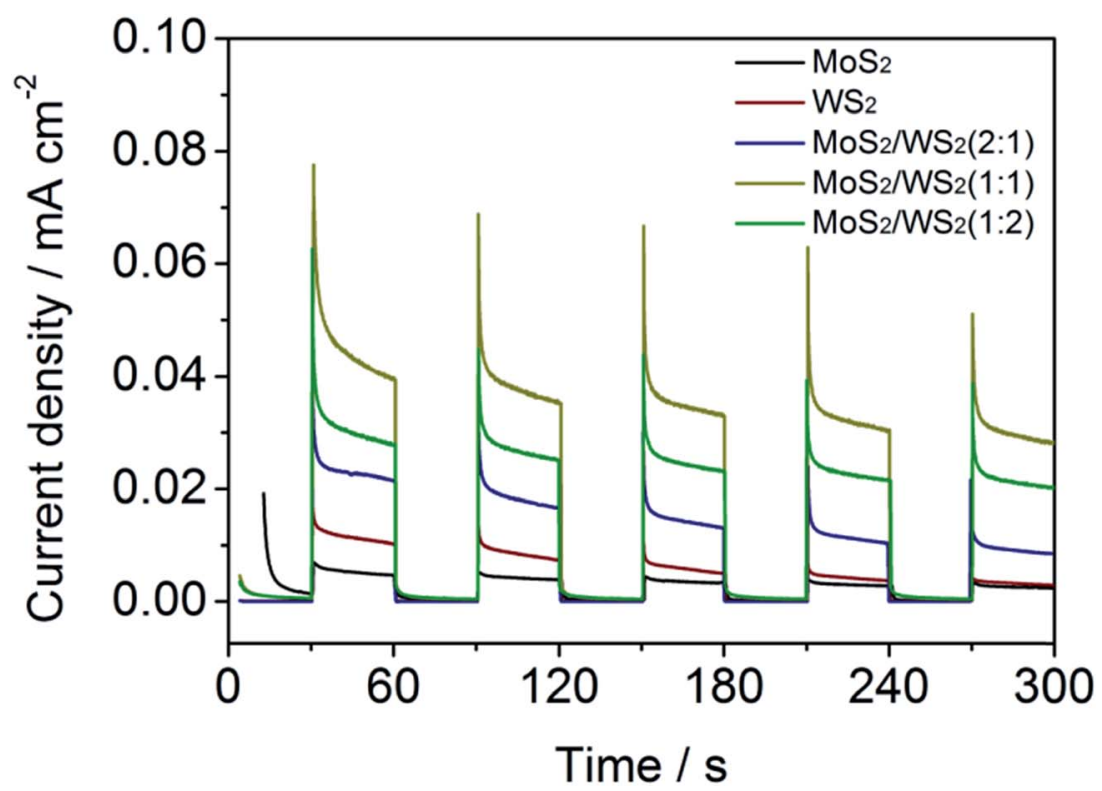

Fig. 6 On-off $J-t$ curves of $\mathrm{MoS}_{2} / \mathrm{WS}_{2}$ vertically aligned structure of nanosheets prepared with different ratio of Mo to W precursor concentration at bias of $0.372 \mathrm{~V}$ vs. RHE in $0.5 \mathrm{~mol} \mathrm{~L}^{-1} \mathrm{H}_{2} \mathrm{SO}_{4}$.

a photocurrent of $\sim 0.04 \mathrm{~mA}$ in the initial stage of photoirradiation, then decreased to $0.03 \mathrm{~mA}$ gradually and maintained the constant photocurrent for more than $7000 \mathrm{~s}$.

Photoelectrocatalysis. The photoelectrocatalytic activity for HER performance of the $\mathrm{MoS}_{2} / \mathrm{WS}_{2}$ electrode was explored in $0.5 \mathrm{M} \mathrm{H}_{2} \mathrm{SO}_{4}$ solution using a three-electrode setup. For comparison, the HER activity of the as-prepared vertically aligned hybrid structures, including $\mathrm{WS}_{2}, \mathrm{MoS}_{2}$ and the $\mathrm{MoS}_{2} /$ $\mathrm{WS}_{2}$ of different mole ratio of Mo: $\mathrm{W}$, were investigated in dark or under light illumination (Fig. 7a). As shown in Fig. 7a, a standalone cathode of $\mathrm{MoS}_{2}$ or $\mathrm{WS}_{2}$ does not show noticeable cathodic current, whether in dark or under illumination condition. As expected, the cathodic polarization curves recorded for the vertically aligned $\mathrm{MoS}_{2} / \mathrm{WS}_{2}$ nanostructures exhibited a comparatively obvious photocurrent in comparison with that of standalone cathode of $\mathrm{MoS}_{2}$ or $\mathrm{WS}_{2}$, and shows greater current under light illumination than in the dark. In addition, the cathodic currents for all $\mathrm{MoS}_{2} / \mathrm{WS}_{2}$ samples are greater than the sum of the cathodic currents of pristine $\mathrm{MoS}_{2}$ and $\mathrm{WS}_{2}$, implying that the combination of $\mathrm{MoS}_{2}$ and $\mathrm{WS}_{2}$ in hybrid structures is synergistic rather than additive. The nanostructured $\mathrm{MoS}_{2} / \mathrm{WS}_{2}$ electrode (Mo/W ratio of 1/1) displays the highest current density among all the tested electrodes. Fig. $7 \mathrm{~b}$ shows the differences in photocurrent density of the 

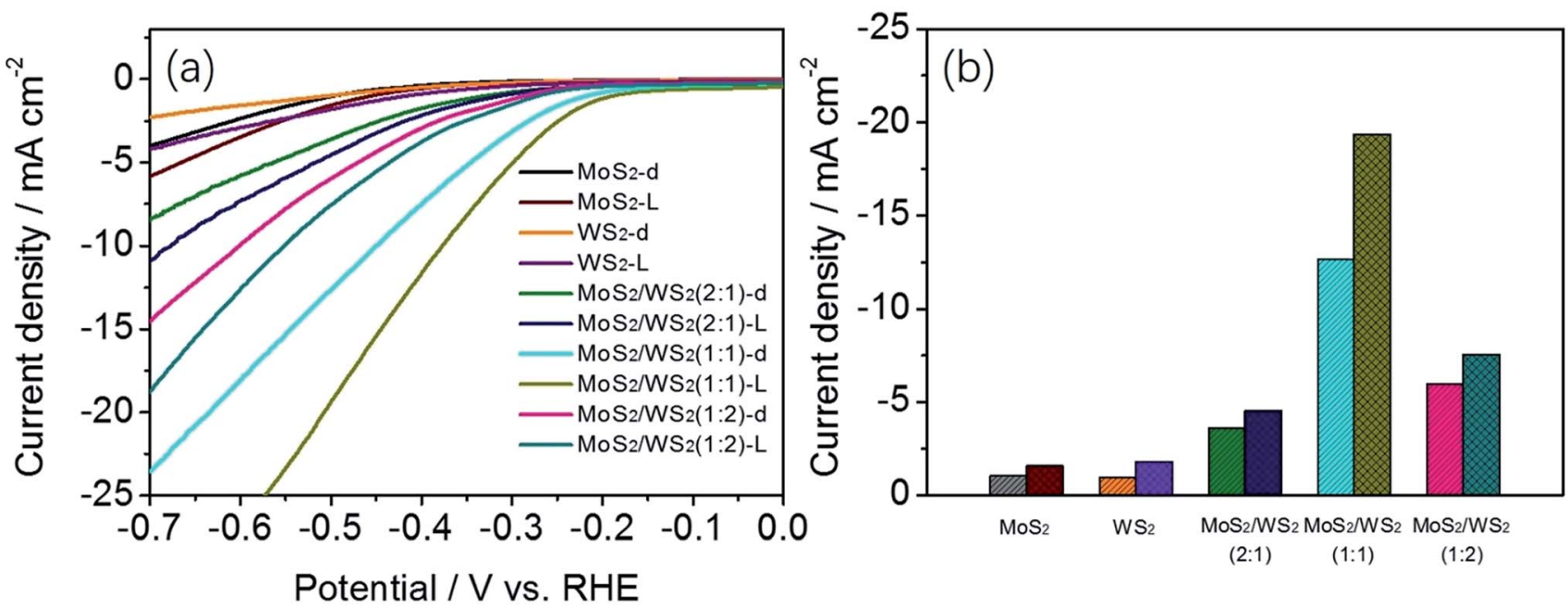

Fig. 7 (a) J-V curves of cathodic polarization of $\mathrm{MOS}_{2}, \mathrm{WS}_{2}$ and $\mathrm{MoS}_{2} / \mathrm{WS}_{2}$ catalysts and (b) histogram of current density at $-0.5 \mathrm{~V}$ ( $v$ s. RHE) of $\mathrm{MoS}_{2}, \mathrm{WS}_{2}$ with different $\mathrm{Mo}: \mathrm{W}$ ratios in dark and under simulated solar light $\left(0.5 \mathrm{M} \mathrm{H}_{2} \mathrm{SO}_{4}\right)$.

catalysts at the potential of $-0.5 \mathrm{~V} v s$. RHE, which is indicated by column charts for clarity. The corresponding Tafel slops are also evacuated, shown in Fig. S7. $\dagger$

The photoelectrocatalytic activity for $\mathrm{MoS}_{2} / \mathrm{WS}_{2}$ hybrid was further evaluated by comparing its potential at $-10 \mathrm{~mA}$ of photo-assistant current density with that from the related literature (Table 1). ${ }^{66-71}$ They are comparable, since all these catalyst samples were prepared in form of ultrathin film on a less conductive substrate except $\mathrm{Au}$ and GCE. From the Table 1, we found that vertically aligned $\mathrm{MoS}_{2} / \mathrm{WS}_{2}$ hybrid shows a better photo assistant electrocatalytic activity on both less conductive and conductive substrate. This improvement in catalytic activity derives from the characteristics of the vertical aligned ultrathin $\mathrm{MoS}_{2} / \mathrm{WS}_{2}$ sheets that integrate energy band alignment and abundant active sites of $\mathrm{MoS}_{2} / \mathrm{WS}_{2}$ catalyst. We also highlighted the photocatalytic activity of $\mathrm{MoS}_{2} / \mathrm{WS}_{2}$ through photocatalytic $\mathrm{H}_{2}$ production. The $\mathrm{H}_{2}$ evolution rates

Table 2 Charge transfer resistance of $\mathrm{MoS}_{2}, \mathrm{WS}_{2}$ and $\mathrm{MoS}_{2} / \mathrm{WS}_{2}$ catalysts in dark and under simulated solar light for HER

\begin{tabular}{lllllll}
\hline & $\mathrm{MoS}_{2}$-d & $\mathrm{MoS}_{2}-\mathrm{L}$ & $\mathrm{WS}_{2}$-d & $\mathrm{WS}_{2}-\mathrm{L}$ & $\mathrm{MoS}_{2} / \mathrm{WS}_{2}-\mathrm{d}$ & $\mathrm{MoS}_{2} / \mathrm{WS}_{2}-\mathrm{L}$ \\
\hline$R_{\mathrm{ct}} / \Omega$ & 55.21 & 54.66 & 80.49 & 65.60 & 23.13 & 17.92
\end{tabular}

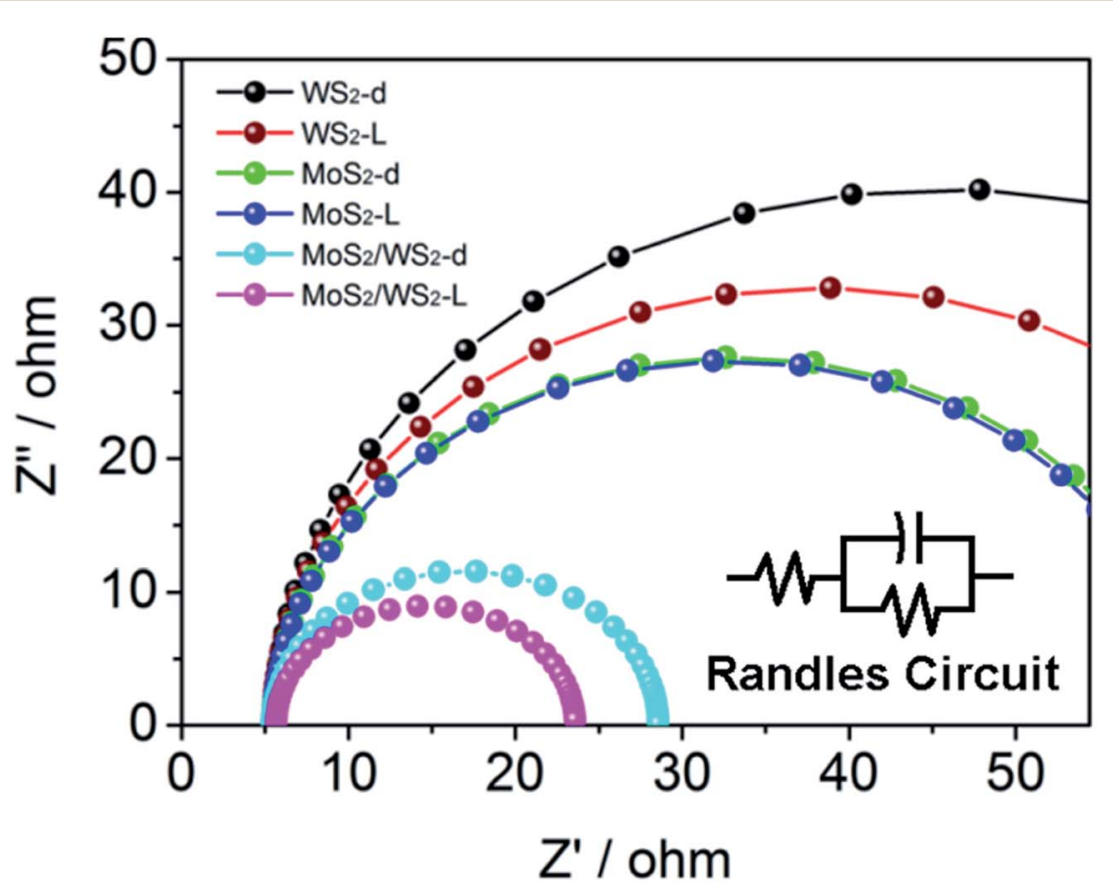

Fig. $8 \mathrm{AC}$ impedance spectroscopy of $\mathrm{MoS}_{2}, \mathrm{WS}_{2}$ and $\mathrm{MoS}_{2} / \mathrm{WS}_{2}(1: 1)$ catalysts in dark and under simulated solar light. 

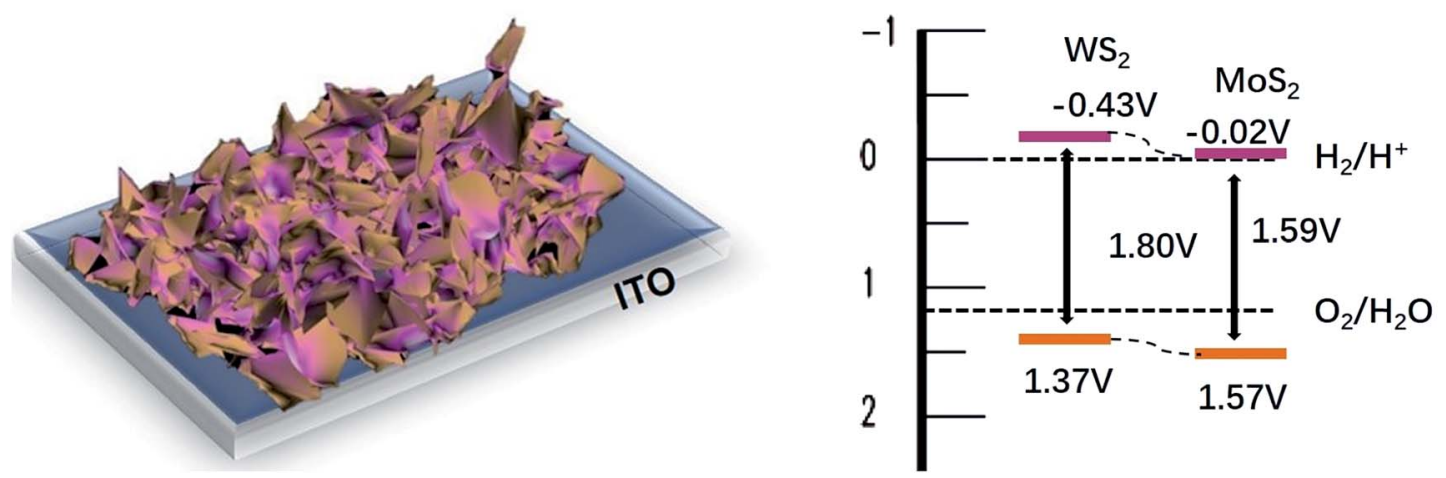

Scheme 1 Schematic illustrations of the charge transfer and separation on the $\mathrm{MoS}_{2} / \mathrm{WS}_{2}$ heterostructure under visible light. The energy band levels are calculated by the $E_{\mathrm{CB}}$ which is measured by flat-band potentials ${ }^{75,76}$ and $E_{\mathrm{g}}$ values of $\mathrm{WS}_{2}$ and $\mathrm{MoS}_{2}$, as shown in Fig. $S 9$ a and b. $\dagger$

under light irradiation without any applied bias for $\mathrm{MoS}_{2} / \mathrm{WS}_{2} /$ ITO manifests the rate of $0.049 \mathrm{ml} \mathrm{h}^{-1}$. It should be noted that the hydrogen evolution rate of $0.049 \mathrm{ml} \mathrm{h}^{-1}$ is produced from the ultrathin $\mathrm{MoS}_{2} / \mathrm{WS}_{2}$ layer of $\sim 223 \mathrm{~nm}$ (Fig. S11†) which dispersed uniformly on the $8 \mathrm{~cm}^{2}$ of surface area of ITO. For comparison with the previous studies, we have to convert $\mathrm{ml} \mathrm{h}^{-1}$ to $\mu \mathrm{mol} \mathrm{g}{ }^{-1} \mathrm{~h}^{-1}$, a customary unit used for hydrogen production rate. It was revealed that the $\mathrm{MoS}_{2} / \mathrm{WS}_{2}$ hierarchical nanosheet possesses significantly high photocatalytic activity $\left(>2065 \mu \mathrm{mol} \mathrm{h}{ }^{-1} \mathrm{~g}^{-1}\right)$. (ESI, Table S1†) noteworthy is, the estimated mass weight of $\mathrm{MoS}_{2} / \mathrm{WS}_{2}$ nanosheet is greater than the actual mass weight because the $\mathrm{MoS}_{2} / \mathrm{WS}_{2}$ structure is hierarchical and poriferous rather than solid, thus leading to an underestimate for $\mathrm{H}_{2}$ evolution production.

Furthermore, the surface kinetics of the as prepared catalysts was evaluated by EIS (Fig. 8). The diameter of the fitted semicircle represents the charge transfer resistance $\left(R_{\mathrm{ct}}\right)$, which is inversely proportional to the rate of charge transfer in the HER process. In a Nyquist plot, the overlaying Nyquist plots of $\mathrm{MoS}_{2} /$ $\mathrm{WS}_{2}(1 / 1)$ displayed a narrower semicircle diameter than that of $\mathrm{WS}_{2}$ or $\mathrm{MoS}_{2}$. In either case, in dark or under light illumination, the $R_{\mathrm{ct}}$ values of $\mathrm{MoS}_{2}$ and $\mathrm{WS}_{2}$ are found to be much higher than $\mathrm{MoS}_{2} / \mathrm{WS}_{2}(17.92 \Omega$ and $23.13 \Omega$ under light illumination and in dark, respectively) (Fig. 8). Compared to $\mathrm{WS}_{2}$, or $\mathrm{MoS}_{2}$, (see Table 2), the significantly reduced $R_{\text {ct }}$ of $\mathrm{MoS}_{2} / \mathrm{WS}_{2}$ shows faster HER kinetics and better catalytic charge-transfer impedance. Undoubtedly, the faster HER surface kinetics of $\mathrm{MoS}_{2} / \mathrm{WS}_{2}$ produces a positive influence on photo- and electrocatalytic activity for HER.

We also measured the electrochemically active surface area (ECSA) of the solid-liquid interfaces through electrochemical double-layer capacitance (EDLC) of the catalytic surface via $\mathrm{CV}^{54}$ The EDLC values of $\mathrm{MoS}_{2}, \mathrm{WS}_{2}$ and $\mathrm{MoS}_{2} / \mathrm{WS}_{2}$ catalysts is 0.423 , 0.245 and $3.05 \mathrm{mF} \mathrm{cm}^{-2}$, respectively, which is obtained by the slop of a straight line extracted from the capacitive current as a function of scan rate. ${ }^{72-74}$ As shown in Fig. S8c and f, $\dagger$ the EDLC value of $3.05 \mathrm{mF} \mathrm{cm}{ }^{-2}$ for the $\mathrm{MoS}_{2} / \mathrm{WS}_{2}$ is much bigger than the values of $\mathrm{MoS}_{2}$ and $\mathrm{WS}_{2}$. (Fig. S8a-d and S8b-e, $\uparrow$ respectively), indicating that $\mathrm{MoS}_{2} / \mathrm{WS}_{2}$ had the largest effective electrochemical area among the three catalysts, and thus presented more active sites.
Mechanism. Based on the above measurements, the enhanced photoelectrocatalytic activity of the $\mathrm{MoS}_{2} / \mathrm{WS}_{2}$ hybrid is attributed to the better electron transportation and higher electrochemically active surface area (ECSA), as well as the proper energy alignment. More importantly, when $\mathrm{MoS}_{2}$ is coupled with $\mathrm{WS}_{2}, \mathrm{MoS}_{2} / \mathrm{WS}_{2}$ hybrid showed a $\mathrm{p}-\mathrm{n}$ junction characteristic of an inverted "V-shape" (see Fig. S9c广). The formation of $\mathrm{p}-\mathrm{n}$ junction region between $\mathrm{MoS}_{2}$ and $\mathrm{WS}_{2}$ is beneficial to the separation of hole-electron pairs excited by photons. A representative structure of photoelectrode studied in this work, together with the relative simplified band diagram is demonstrated, as shown in see Scheme 1. When the heteronanostructure is constructed, the built-in electric field forms, and the hole-electron pairs, excited by photons, will immediately separate under internal electrostatic field in heterojunction region. Together with matching of band edges between $\mathrm{WS}_{2}$ and $\mathrm{MoS}_{2}, \mathrm{MoS}_{2} / \mathrm{WS}_{2}$ showed the improved photo-and electrocatalytic activity due to the restrained recombination. The best performance of catalyst for mole ratio of $\mathrm{Mo} / \mathrm{W}$ of $1 / 1$ is probably ascribed to compromise the contradictory relation between active sites and conductivity. (ESI Fig. S10 $†$ ) in addition, uniquely designed electrode structure with the vertical array of the $\mathrm{MoS}_{2} / \mathrm{WS}_{2}$ ultrathin nanosheets brings in more active sites along with the optimized conductivity and reduced gas bubble adhesion, thus leading to high photoelectrochemical properties for HER.

\section{Conclusion}

$\mathrm{MoS}_{2} / \mathrm{WS}_{2}$ nanosheets with a vertically aligned structure fabricated directly on indium tin oxide (ITO) substrate were fabricated through a facile one-pot hydrothermal reaction. The hybrid nanosheets of $\mathrm{MoS}_{2} / \mathrm{WS}_{2}$ supplied numbers of active sites with proper defects since the elements of $\mathrm{W}$ doped $\mathrm{MoS}_{2}$. Favorable band alignment, as well as high-quality, intimate p-n heterojunction between $\mathrm{MoS}_{2}$ and $\mathrm{WS}_{2}$, provides an effective carrier separation in this composite based photoelectric device. Therefore, the $\mathrm{MoS}_{2} / \mathrm{WS}_{2}$ nanosheets show better visible light activities than that of either pristine $\mathrm{WS}_{2}$ or $\mathrm{MoS}_{2}$ nanostructures. The improvements in both electro- and photocatalytic activities for HER are ascribed to the integration of 
energy band alignment and abundant active sites derived of the vertically aligned $\mathrm{MoS}_{2} / \mathrm{WS}_{2}$ nanosheets. The rational use of the $\mathrm{MoS}_{2} / \mathrm{WS}_{2}$ cathode provided a new avenue toward achieving an enhanced electrocatalytic activity by photo-assistance.

\section{Conflicts of interest}

There are no conflict to declare.

\section{References}

1 C. Tsai, F. Abild-Pedersen and J. K. Norskov, Nano Lett., 2014, 14, 1381-1387.

2 A. Ejigu, I. A. Kinloch, E. Prestat and R. A. W. Dryfe, J. Mater. Chem. A, 2017, 5, 11316-11330.

3 H. Huang, L. Chen, C. Liu, X. Liu, S. Fang, W. Liu and Y. Liu, J. Mater. Chem. A, 2016, 4, 14577-14585.

4 H. Zhou, F. Yu, J. Sun, R. He, Y. Wang, C. F. Guo, F. Wang, Y. Lan, Z. Ren and S. Chen, J. Mater. Chem. A, 2016, 4, 9472-9476.

5 D. A. Reddy, H. Park, S. Hong, D. P. Kumar and T. K. Kim, J. Mater. Chem. A, 2017, 5, 6981-6991.

6 T. An, Y. Wang, J. Tang, W. Wei, X. Cui, A. M. Alenizi, L. Zhang and G. Zheng, J. Mater. Chem. A, 2016, 4, 1343913443.

7 Y. Xu, L. Wang, X. Liu, S. Zhang, C. Liu, D. Yan, Y. Zeng, Y. Pei, Y. Liu and S. Luo, J. Mater. Chem. A, 2016, 4, 1652416530.

8 Q. Wang, Z. Liu, X. Zhang, H. Zhao, C. Luo, H. Jiao and Y. Du, J. Mater. Chem. A, 2017, 5, 9523-9527.

9 W. Maijenburg, M. Regis, A. N. Hattori, H. Tanaka, K. S. Choi and J. E. Ten Elshof, ACS Appl. Mater. Interfaces, 2014, 6, 2003-2010.

10 Y. Yan, B. Xia, X. Qi, H. Wang, R. Xu, J. Y. Wang, H. Zhang and X. Wang, Chem. Commun., 2013, 49, 4884-4886.

11 Y. Yan, B. Xia, X. Ge, Z. Liu, J. Y. Wang and X. Wang, ACS Appl. Mater. Interfaces, 2013, 5, 12794-12798.

12 D. Voiry, M. Salehi, R. Silva, T. Fujita, M. Chen, T. Asefa, V. B. Shenoy, G. Eda and M. Chhowalla, Nano Lett., 2013, 13, 6222-6227.

13 F.-K. Meng, J.-T. Li, S. K. Cushing, M. Zhi and N.-Q. Wu, J. Am. Chem. Soc., 2013, 135, 10286-10289.

14 G. Morales-Guio, S. D. Tilley, H. Vrubel, M. Gratzel and X. Hu, Nat. Commun., 2014, 5, 3059.

15 H. V. a. X. Hu, ACS Catal., 2013, 3, 2002-2011.

16 Y. Zhao, Y. Zhang, Z. Yang, Y. Yan and K. Sun, Sci. Technol. Adv. Mater., 2013, 14, 043501.

17 D. Merki and X. Hu, Energy Environ. Sci., 2011, 4, 3878.

18 S. Trasatti, J. Electroanal. Chem., 1971, 33, 350-378.

19 Sobczynski, A. Yildiz, A. J. Bard, A. Campion, M. A. Fox, T. Mallouk, S. E. Webber and J. M. White, J. Phys. Chem., 1988, 92, 2311-2315.

20 J. Bonde, P. G. Moses, T. F. Jaramillo, K. Nørskovb and I. Chorkendorff, Faraday Discuss., 2009, 140, 219-231.

21 A.-B. Laursen, S. Kegnæs, S. Dahl and I. Chorkendorff, Energy Environ. Sci., 2012, 5, 5577-5591.
22 Y.-G. Li, H.-L. Wang, L.-M. Xie, Y.-Y. Liang, G.-S. Hong and H.-J. Dai, J. Am. Chem. Soc., 2011, 133, 7296-7299.

23 J.-K. Lee, W. Lee, T.-J. Yoon, G.-S. Park and J.-H. Choy, J. Mater. Chem., 2002, 12, 614-618.

24 Q. H. Wang, K. Kalantar-Zadeh, A. Kis, J. N. Coleman and M. S. Strano, Nat. Nanotechnol., 2012, 7, 699-712.

25 D. Jing and L. Guo, Catal. Commun., 2007, 8, 795-799.

26 X. Zong, J. Han, G. Ma, H. Yan, G. Wu and C. Li, J. Phys. Chem. C, 2011, 115, 12202-12208.

27 Y. Zhong, G. Zhao, F. Ma, Y. Wu and X. Hao, Appl. Catal., B, 2016, 199, 466-472.

28 X. Zong, H. Yan, G. Wu, G. Ma, F. Wen, L. Wang and C. Li, J. Am. Chem. Soc., 2008, 130, 7176-7177.

29 K. Chang, Z. Mei, T. Wang, Q. Kang, S. Ouyang and J. Ye, ACS Nano, 2014, 8, 7078-7087.

30 R. Tang, R. Yin, S. Zhou, T. Ge, Z. Yuan, L. Zhang and L. Yin, J. Mater. Chem. A, 2017, 5, 4962-4971.

31 X. Hong, J. Kim, Su-F. Shi, Y. Zhang, C. Jin, Y. Sun, S. Tongay, J. Wu, Y. Zhang and F. Wang, Nat. Nanotechnol., 2014, 9, 682.

32 K. Chen, X. Wan, W. Xie, J. Wen, Z. Kang, X. Zeng, H. Chen and J. Xu, Adv. Mater., 2015, 27, 6431-6437.

33 H. M. Hill, A. F. Rigosi, K. T. Rim, G. W. Flynn and T. F. Heinz, Nano Lett., 2016, 16, 4831-4837.

34 K. Kośmider and J. Fernández-Rossier, Phys. Rev. B: Condens. Matter Mater. Phys., 2013, 87, 075451.

35 A. Kuc, N. Zibouche and T. Heine, Phys. Rev. B: Condens. Matter Mater. Phys., 2011, 83, 245213.

36 B. Hinnemann, P. G. Moses, J. Bonde, K. P. Jørgensen, J. H. Nielsen, S. Horch, I. Chorkendorff and J. K. Nørskov, J. Am. Chem. Soc., 2005, 127, 5308-5309.

37 H. Tributsch and B. B. Gesell, Ber. Bunsen-Ges. Phys. Chem., 1977, 81, 361-369.

38 H. Tributsch and J. C. Bennett, J. Electroanal. Chem., 1977, 81, 97-111.

39 B. Hinnemann, J. K. Nørskov and H. Topsøe, J. Phys. Chem. B, 2005, 109, 2245-2253.

40 Z. Wu, B. Fang, A. Bonakdarpour, A. Sun, D. P. Wilkinson and D. Wang, Appl. Catal., B, 2012, 125, 59-66.

41 D. Voiry, H. Yamaguchi, J. Li, R. Silva, D. C. Alves, T. Fujita, M. Chen, T. Asefa, V. B. Shenoy, G. Eda and M. Chhowalla, Nat. Mater., 2013, 12, 850-855.

42 C. L. Choi, J. Feng, Y. Li, J. Wu, A. Zak, R. Tenne and H. Dai, Nano Res., 2013, 6, 921-928.

43 X. Hai, W. Zhou, K. Chang, H. Pang, H. Liu, L. Shi, F. Ichihara and J. Ye, J. Mater. Chem. A, 2017, 5, 8591-8598.

44 Y. Yu, S. Huang, Y. Li, S. Steinmann, W. Yang and L. Cao, Nano Lett., 2014, 14, 553-558.

45 Z. Lu, W. Zhu, X. Yu, H. Zhang, Y. Li, X. Sun, X. Wang, H. Wang, J. Wang, J. Luo, X. Lei and L. Jiang, Adv. Mater., 2014, 26, 2683-2687, 2615.

46 Y. Yan, B. Xia, Z. Xu and X. Wang, ACS Catal., 2014, 4, 16931705.

47 Y. H. Chang, F. Y. Wu, T. Y. Chen, C. L. Hsu, C. H. Chen, F. Wiryo, K. H. Wei, C. Y. Chiang and L. J. Li, Small, 2014, 10, 895-900. 
48 P. D. Tran, S. S. Pramana, V. S. Kale, M. Nguyen, S. Y. Chiam, S. K. Batabyal, L. H. Wong, J. Barber and J. Loo, Chemistry, 2012, 18, 13994-13999.

49 J.-F. Xie, H. Zhang, S. Li, R.-X. Wang, X. Sun, M. Zhou, J.-F. Zhou, X.-W. Lou and Y. Xie, Adv. Mater., 2013, 25, 5807-5813.

50 S.-K. Park, D. Y. Chung, D. Ko, Y.-E. Sung and Y. Piao, J. Mater. Chem. A, 2016, 4, 12720-12725.

51 N. Zhang, S. Gan, T. Wu, W. Ma, D. Han and L. Niu, ACS Appl. Mater. Interfaces, 2015, 7, 12193-12202.

52 Y. Sun, K. Liu, X. Hong, M. Chen, J. Kim, S. Shi, J. Wu, A. Zettl and F. Wang, Nano Lett., 2014, 14, 5329-5334.

53 Q. Ding, F. Meng, C. R. English, M. Caban-Acevedo, M. J. Shearer, D. Liang, A. S. Daniel, R. J. Hamers and S. Jin, J. Am. Chem. Soc., 2014, 136, 8504-8507.

54 A. Lukowski, A. S. Daniel, F. Meng, A. Forticaux, L. Li and S. Jin, J. Am. Chem. Soc., 2013, 10274-10277.

55 U. Maitra, U. Gupta, M. De, R. Datta, A. Govindaraj and C. N. Rao, Angew. Chem., Int. Ed. Engl., 2013, 52, 1305713061.

56 Q. Liu, X. Li, Q. He, A. Khalil, D. Liu, T. Xiang, X. Wu and L. Song, Small, 2015, 11, 5556-5564.

57 Q. Liu, X. Li, Z. Xiao, Y. Zhou, H. Chen, A. Khalil, T. Xiang, J. Xu, W. Chu, X. Wu, J. Yang, C. Wang, Y. Xiong, C. Jin, P. M. Ajayan and L. Song, Adv. Mater., 2015, 27, 4837-4844. 58 L. U. J. Bo, Z. Z. Wei and L. H. Gui, China Tungsten Ind., 2005, 20, 33-36.

59 G. Kulmukhamedov, A. Zelikman and G. Verevkin, Zh. Anal. Khim., 1991, 36, 2981-2985.

60 B. E. Erickson and G. R. HELZ, Geochim. Cosmochim. Acta, 2000, 64, 1149-1158.

61 F. Wypych and R. Schöllhorn, J. Chem. Soc., Chem. Commun., 1992, 1386-1388.
62 C. Liu, L. Wang, Y. Tang, S. Luo, Y. Liu, S. Zhang, Y. Zeng and Y. Xu, Appl. Catal., B, 2015, 164, 1-9.

63 S. Li, S. Wang, D.-M. Tang, W. Zhao, H. Xu, L. Chu, Y. Bando, D. Golberg and G. Eda, Applied Materials Today, 2015, 1, 6066.

64 S. Hernandez, D. Hidalgo, A. Sacco, A. Chiodoni, A. Lamberti, V. Cauda, E. Tresso and G. Saracco, Phys. Chem. Chem. Phys., 2015, 17, 7775-7786.

65 J. O. M. Bockris and J. E. C. Potter, J. Electrochem. Soc., 1952, 99, 169-186.

66 X. Zhang, Y. Yang, S. Ding, W. Que, Z. Zheng and Y. Du, Inorg. Chem., 2017, 56, 3386-3393.

67 Y.-F. Zhao, Z.-Y. Yang, Y.-X. Zhang, L. Jing, X. Guo, Z.-T. Ke, P.-W. Hu, G.-X. Wang, Y.-M. Yan and K.-N. Sun, J. Phys. Chem. C, 2014, 118, 14238-14245.

68 J. M. Woods, Y. Jung, Y. Xie, W. Liu, Y. Liu, H. Wang and J. J. Cha, ACS Nano, 2016, 10, 2004-2009.

69 Y. Qi, Q. Xu, Y. Wang, B. Yan, Y. Ren and Z. Chen, ACS Nano, 2016, 10, 2903-2909.

70 J. Shi, R. Tong, X. Zhou, Y. Gong, Z. Zhang, Q. Ji, Y. Zhang, Q. Fang, L. Gu, X. Wang, Z. Liu and Y. Zhang, Adv. Mater., 2016, 28, 10664-10672.

71 S. Xu, D. Li and P. Wu, Adv. Funct. Mater., 2015, 25, 11271136.

72 S. Trasatti and O. A. Petrii, Pure Appl. Chem., 1991, 63, 711734.

73 J. D. Benck, Z. Chen, L. Y. Kuritzky, A. J. Forman and T. F. Jaramillo, ACS Catal., 2012, 2, 1916-1923.

74 R. Boggio, A. Garugati and S. Trasatti, J. Appl. Electrochem., 1987, 17, 828-840.

75 S. J. Hong, S. Lee, J. S. Jang and J. S. Lee, Energy Environ. Sci., 2011, 4, 1781.

76 H. Huang, D. Li, Q. Lin, W. Zhang, Y. Hao, Y. Chen, M. Sun and A. Fu, Environ. Sci. Technol., 2009, 43, 4164-4168. 